\title{
Dosimetric analysis of chimeric monoclonal antibody cMOv18 IgG in ovarian carcinoma patients after intraperitoneal and intravenous administration
}

\author{
W.C.A.M. Buijs ${ }^{1}$, J.G. Tibben², O.C. Boerman'1, C.F.M. Molthoff ${ }^{3}$, L.F.A.G. Massuger², E.B. Koenders ${ }^{1}$, C.P.T. Schijf2 \\ J.A. Siegel ${ }^{1}$, F.H.M. Corstens ${ }^{1}$ \\ 1 Department of Nuclear Medicine, University Hospital Nijmegen, The Netherlands \\ 2 Department of Obstetrics and Gynaecology, University Hospital Nijmegen, The Netherlands \\ 3 Department of Obstetrics and Gynaecology, University Hospital Vrije Universiteit, Amsterdam, The Netherlands
}

Received 10 July and in revised form 17 August 1998

\begin{abstract}
In this study the potential of intraperitoneal (i.p.) and intravenous (i.v.) administration of chimeric iodine-131-labelled MOv18 IgG for radioimmunotherapy was determined. The dosimetry associated with both routes of administration of cMOv18 IgG was studied in patients. Eight patients suspected of having ovarian carcinoma received $150 \mathrm{MBq}{ }^{131} \mathrm{I}-\mathrm{cMOv} 18 \mathrm{IgG}$ i.p. Blood and urine were collected and serial gamma camera images were acquired. Another group of four patients received $7.5 \mathrm{MBq}{ }^{131} \mathrm{I}-\mathrm{cMOv} 18 \mathrm{IgG}$ i.v. For all patients, tissue biopsies were obtained at surgery. Activity in the blood after i.p. administration was described by a bi-exponential curve with a mean uptake and elimination half-life of $6.9 \pm 3.2 \mathrm{~h}$ and $160 \pm 45 \mathrm{~h}$, respectively. For i.v. infusion the mean half-life for the elimination phase was $103 \pm 12 \mathrm{~h}$. Cumulative excretion in the urine was $17 \% \pm 3 \%$ ID and $21 \% \pm 7 \%$ ID in $96 \mathrm{~h}$ for i.p. and i.v. administration, respectively. Scintigraphic images after i.p. administration showed accumulation in ovarian cancer lesions, while all other tissues showed decreasing activity with time. Tumour uptake determined in the ovarian cancer tissue specimens ranged from $3.4 \%$ to $12.3 \%$ ID/kg for i.p. administration and from $3.6 \%$ to $5.4 \%$ ID/kg for i.v. administration. Dosimetric analysis of the data indicated that $1.7-4.3 \mathrm{mGy} / \mathrm{MBq}$ and 1.7-2.2 $\mathrm{mGy} / \mathrm{MBq}$ can be guided to solid or ascites cells after i.p. and i.v. administration, respectively. Assuming that an absorbed dose to the bone marrow of 2 Gy will be dose limiting, a total activity of $4.1 \mathrm{GBq}^{131}{ }^{13}$ cMOv18 IgG can be administered safely via the i.p. route and $3.5 \mathrm{GBq}$ via the i.v. route. At this maximal tolerated dose, a maximum absorbed dose to 1-g tumours in the peritoneal cavity of 18 and 8 Gy can be reached after i.p. and i.v. administration, respectively. For the i.p. route of administration, dose estimates for the tumour
\end{abstract}

Correspondence to: W.C.A.M. Buijs, Department of Nuclear Medicine, University Hospital Nijmegen, PO Box 9101, 6500 HB Nijmegen, The Netherlands are even higher when the electron dose of the peritoneal activity is also taken into account: total doses to the tumour of $30 \mathrm{~Gy}$ and $22 \mathrm{~Gy}$ will be absorbed at the tumour surface and at $0.2 \mathrm{~mm}$ depth, respectively. In conclusion, therapeutic tumour doses can be achieved with ${ }^{131} \mathrm{I}-$ cMOv18 IgG in patients with intraperitoneal ovarian cancer lesions with no normal organ toxicity. The i.p. route of administration seems to be preferable to i.v. administration.

Key words: Internal radiation dosimetry - Radionuclides - Intraperitoneal - Radioimmunotherapy - Ovarian cancer

Eur J Nucl Med (1998) 25:1552-1561

\section{Introduction}

Radioimmunoscintigraphy (RIS) studies in ovarian cancer patients have demonstrated preferential tumour localisation of several radiolabelled anti-tumour monoclonal antibodies (MAbs) in vivo. In RIS with iodine-131 labelled murine MOv18 $\mathrm{IgG}$ an overall sensitivity of $84 \%$ was achieved [1]. Also the chimeric form of MOv18 (cMOv18) has been studied extensively in experimental models and in ovarian cancer patients [2-4].

Several studies have focussed on guiding therapeutic doses of radioactivity to ovarian cancer tumours with anti-tumour MAbs $[5,6]$. For therapeutic purposes radiolabelled MAbs can be administered either systemically or locoregionally. After intravenous (i.v.) administration all disseminated tumour lesions can be reached [7, 8], while locoregional administration may be favourable in the treatment of diseases which are known to spread locally. Ovarian cancer is a malignancy whose spread initially is confined to the peritoneal cavity [1]. In the majority of ovarian cancer radioimmunotherapy (RIT) studies, the 
radiolabeled antibody has been administered intraperitoneally (i.p.) [5]. Dosimetric analysis of biodistribution studies in mice with ovarian cancer xenografts indicated that higher radiation doses were guided to solid tumour deposits after i.p. administration [9]. Several studies in ovarian carcinoma patients indicated that therapeutic responses can be achieved in patients with small tumour deposits after i.p. administration [5, 6]. Intraperitoneal administration of radiolabelled MAbs may reduce the toxicity to the dose-limiting organ (e.g. bone marrow), allowing the administration of higher doses [1, 9].

The aim of the present study was to investigate the dosimetry associated with the i.p. and i.v. administration of radioiodinated cMOv18 $\mathrm{IgG}$ in ovarian cancer patients. Because the potential for therapy was a major consideration, the relation between tumour and red marrow dose was analysed for both the i.p. and the i.v. route of administration [10,11]. Special emphasis was given to estimation of the dose to small tumour lesions, because small tumours are considered to be an optimal target for RIT $[12,13]$.

\section{Materials and methods}

Patients. Patients suspected of having ovarian cancer who were scheduled to undergo exploratory laparotomy were entered in the study. Patients had to be over the age of 18 years and had to have a life expectancy of at least 3 months. The study was conducted with the approval of the Internal Review Board of the University
Hospital Nijmegen or the University Hospital Vrije Universiteit Amsterdam, The Netherlands. Written informed consent was obtained from each patient prior to study entry.

Study design. Access to the i.p. cavity was obtained by insertion of a Verres needle under local anaesthesia. If present, the ascites was withdrawn from the peritoneal cavity prior to infusion. Patients received an i.p. infusion of approximately 1.51 of normal saline $\left(37^{\circ} \mathrm{C}\right)$ followed by a single i.p. infusion of $150 \mathrm{MBq}{ }^{131} \mathrm{I}-$ cMOv18 IgG in $50 \mathrm{ml}$ of saline. Protein doses of $30-80 \mathrm{mg}$ were administered. The thyroid was blocked with $100 \mathrm{mg}$ potassium iodide two times a day and potassium perchlorate $200 \mathrm{mg}$ four times a day orally starting $4 \mathrm{~h}$ before the infusion and continuing for 2 weeks. Patient characteristics are summarized in Table 1. For comparison, another group of patients received $7.5 \mathrm{MBq}{ }^{131} \mathrm{I}-$ cMOv18 IgG by i.v. infusion during $2 \mathrm{~h}$ [14].

Blood samples were collected just prior to the antibody administration and at various time points until surgery. The biological half-life of disappearance from the blood was calculated using non-linear least square regression analysis. To determine renal excretion, urine was collected in 24-h fractions. All activity data were corrected for physical decay.

After i.p. administration anterior and posterior total body images were obtained at five different time points. Images were obtained with a dual-headed gamma camera (Type MultiSpect2, Siemens Inc., Hoffman Estates, Ill., USA) equipped with high-energy collimators.

Surgery was performed 6-8 days post infusion in all patients. The tumour status was carefully mapped and examined by histological techniques. Ascites and peritoneal washings were collected. Suspected tissues were either removed or biopsied. If feasible, tissue samples of muscle, skin and normal omentum were obtained. All tissues removed at surgery were weighed and the

Table 1. Patient characteristics

\begin{tabular}{|c|c|c|c|c|c|}
\hline $\begin{array}{l}\text { Patient } \\
\text { no. }\end{array}$ & $\begin{array}{l}\text { MAb } \\
(\mathrm{mg})\end{array}$ & $\begin{array}{l}\text { Age } \\
(\mathrm{yr})\end{array}$ & $\begin{array}{l}\text { FIGO } \\
\text { stage }^{\text {a }}\end{array}$ & Histologyb & $\begin{array}{l}\text { Diff. } \\
\text { grade }\end{array}$ \\
\hline \multicolumn{6}{|c|}{ Intraperitoneal administration } \\
\hline 1 & 15 & 64 & NA & Serous cystadenoma & NA \\
\hline 2 & 15 & 46 & IIIa & $\begin{array}{l}\text { Malignant mixed } \\
\text { Müllerian tumour }\end{array}$ & III \\
\hline 3 & 15 & 68 & Ic & Corpus carcinoma & II \\
\hline 4 & 30 & 37 & NA & Benign teratoma & NA \\
\hline 5 & 30 & 18 & NA & $\begin{array}{l}\text { Non-Hodgkin } \\
\text { lymphoma }\end{array}$ & NA \\
\hline 6 & 30 & 41 & NA & Serous cystadenoma & NA \\
\hline 9 & 50 & 45 & IIIc & $\begin{array}{l}\text { Serous } \\
\text { cystadenocarcinoma }\end{array}$ & III \\
\hline 10 & 80 & 78 & IIc & $\begin{array}{l}\text { Endometrioid } \\
\text { adenocarcinoma }\end{array}$ & III \\
\hline \multicolumn{6}{|c|}{ Intravenous administration } \\
\hline 8 & 30 & 53 & IIIc & Clear cell (coeloma) & II \\
\hline 11 & 30 & 45 & NA & Benign & - \\
\hline 12 & 50 & 43 & IIIc & Serous & III \\
\hline 15 & 75 & 55 & IIIc & Serous & III \\
\hline
\end{tabular}

NA, not applicable

a Stage at first diagnosis according to the Féderation Internationale de Gynaecology et Obstetrique

b Pathological classification of epithelial ovarian carcinoma at first diagnosis: grade I, well-differentiated carcinoma; grade II, moderately differentiated carcinoma; grade III, poorly differentiated carcinoma 
Table 2. Fractional blood volume for organs and tissue inside the abdominal ROI

\begin{tabular}{|c|c|c|c|}
\hline & $\begin{array}{l}\text { Weight }{ }^{\mathrm{a}} \\
\text { (g) }\end{array}$ & $\begin{array}{l}\text { Blood content } \\
(\mathrm{ml} / \mathrm{kg})\end{array}$ & $\begin{array}{l}\text { Fractional } \\
\text { blood volume }\end{array}$ \\
\hline Liver & 1800 & 139 & 0.0481 \\
\hline Spleen & 180 & 500 & 0.0173 \\
\hline Gallbladder wall & 11 & 150 & 0.00032 \\
\hline Stomach wall & 150 & 150 & 0.0043 \\
\hline Small intestine wall & 640 & 150 & 0.0185 \\
\hline Large intestine wall & 370 & 150 & 0.0107 \\
\hline Kidneys & 310 & 226 & 0.0135 \\
\hline Urinary bladder wall & 45 & 150 & 0.0013 \\
\hline Uterus & 80 & 150 & 0.0023 \\
\hline Ovaries & 11 & 150 & 0.00032 \\
\hline Muscle ${ }^{c)}$ & 5600 & - & 0.0269 \\
\hline Skinc, d) & 470 & - & 0.018 \\
\hline Trabecular bonec) & 220 & 25 & 0.00158 \\
\hline Cortical bonec) & 497 & 28 & 0.00268 \\
\hline Marrowc) & 725 & 127 & 0.0177 \\
\hline Total fractional blood volume & & & 0.1835 \\
\hline
\end{tabular}

a Data derived from ICRP 23, Table 105 [17]

b Data derived from ICRP 53, Table A.2 [18]

${ }^{\mathrm{c}}$ For muscle, skin, bone and red marrow a proportionate part of the total organ weight and organ blood content is estimated to be present in the abdomen ROI

${ }^{d}$ It was assumed that the body surface of the abdominal region was approximately $18 \%$ of the total body surface and that the total skin receives $10 \%$ of the heart minute volume amount of radioactivity of ${ }^{131}$ I was measured in a well-type gamma counter. The total activity in the whole resected tumour was measured, as well as activity in selected small tumour deposits.

Dosimetric analysis. Methods consistent with those recommended by the MIRD Committee of the Society of Nuclear Medicine were used to determine the absorbed dose to the normal organs, tumour and the whole body [15]. The absorbed doses in organs were expressed as $\mathrm{mGy} / \mathrm{MBq}$.

For quantification of activity from gamma camera images after i.p. administration, the conjugate view counting technique was used [16]. A correction for differences in attenuation between abdomen, thorax and extremities was performed based on transmission scans. After correction for physical decay, the retention of activity in the abdomen, peritoneal cavity or total body region of interest (ROI) was expressed as a percentage of the injected dose (\% ID), setting the initial total body scintigraphic recording as $100 \%$ injected dose.

It was assumed that on the first image ( $1 \mathrm{~h}$ post infusion), all activity infused via the i.p. route of administration was localised in the abdomen. During the first $24 \mathrm{~h}$ post infusion (p.i.) the intraabdominal organs were surrounded by activity. During this time virtually no radioactivity had entered the circulation. The count rate data from the ROIs of the abdominal organs, such as liver, spleen and kidney, during this time do not reflect radioactivity uptake, but rather represent the radioactivity surrounding these organs. At later time points no accumulation of radioactivity in the abdominal organs was observed, and it was assumed that the radioactivity in the abdominal organs represented blood perfusion only.

The activity in the peritoneal cavity was estimated, assuming that the activity in the abdomen ROI was partly the result of blood perfusion of the organs in the abdominal region. The fractional blood volume (FBV) in the organs situated in the ROI of the abdomen was estimated from data published in ICRP 23 and ICRP 53
[17, 18], (Table 2). The blood content of intra-abdominal organs was assumed to be $150 \mathrm{ml} / \mathrm{kg}$ tissue in cases when published data were not available. The sum of the FBVs for the abdominal organs was 0.1835 (Table 2). Therefore $20 \%$ of the total blood activity was assumed to be present in the abdominal organs. Assuming that no activity was present in the urinary bladder at the time of imaging, the retention of radioactivity in the peritoneal cavity was calculated for each time point according the formula:

Retention in peritoneal cavity (\%ID)

$\%$ ID in the ROI of the abdomen $-0.2 \times$ total blood activity

$$
-\% \text { ID in the ROI of the tumour }
$$

For each patient, the absorbed dose to the target organs, due to peritoneal cavity activity, was calculated as the product of the residence time (area under the time-activity curve of the peritoneal cavity) and the photon S-values for ${ }^{131}$ I in the peritoneal cavity as calculated by Watson et al. [19].

The absorbed doses to the target organs due to activity in the total body minus the peritoneal cavity was calculated using the MIRDOSE3 program [20], selecting the anthropomorphic phantom for the "adult female". The urinary bladder, the red marrow, the ovarian tumours and the "rest of the body" were considered as source organs following i.p. infusion of the MAb. The residence time of the "rest of the body" was calculated as the residence time of the total body minus the sum of the residence times of the peritoneal cavity, the red marrow and the ovarian tumours. A uniform distribution of the activity in the "rest of the body" was assumed. The residence time for the urinary bladder was calculated from the activity excreted in the urine up to $144 \mathrm{~h}$ p.i., using a voiding interval of $4 \mathrm{~h}$.

For each target organ the sum of the MIRDOSE3 doses and the dose due to the activity in the peritoneal cavity was calculated.

For the i.v. route of administration, the urinary bladder, the red marrow and the "rest of the body" were considered as source or- 
gans. The retention in the total body at 24 and $96 \mathrm{~h}$ p.i. was calculated as the difference between the injected activity and the cumulative urinary excretion at those time points. The absorbed organ doses were calculated from the residence times of the source organs pooled for all patients, using the MIRDOSE3 program [20].

Red marrow dosimetry. Since no activity was visualised in the skeleton and/or the bone marrow, it was assumed that blood activity was the primary contributor to the absorbed dose in the red marrow. It was also assumed that the marrow activity concentration was $25 \%$ of the blood activity concentration [21]. For an adult female the whole blood and red marrow were assumed to weigh $4100 \mathrm{~g}$ and $1120 \mathrm{~g}$, respectively $[17,20]$. The residence time of the red marrow could therefore be calculated as $6.8 \%$ of the blood residence time. In RIT with ${ }^{131}$ I-labelled MAbs, the maximum amount of activity which can be administered safely is assumed to be the activity dose that results in a 2-Gy dose to the red marrow $[11,22]$. The dose to all other tissues was calculated using this maximum amount of activity. The absorbed dose to the red marrow was estimated using the adult female phantom in the MIRDOSE3 program [20].

Effective dose. For the i.p. route of administration the effective dose was calculated from the mean values of 24 normal organ absorbed doses according to the methods given in ICRP 60 [23]. The contributions of both the activity in the peritoneal cavity and the activity in "the total body minus the peritoneal cavity" to the organ doses were included. For the i.v. route of administration the effective dose was calculated using the MIRDOSE3 program.

Tumour dose. Three different contributions to the absorbed dose in the tumours were included: penetrating radiation due to activity in the whole body, non-penetrating radiation due to activity in tumour tissue as measured ex vivo and, for the i.p. route, the electron dose due to the peritoneal cavity wall.

Due to the similarity in location and size, the ovaries were selected as the surrogate for the intraperitoneal tumours for dose estimates due to penetrating radiation. The total tumour absorbed dose from penetrating radiation was calculated as the sum of the dose from activity in the peritoneal cavity and the absorbed dose from the activity outside the peritoneal cavity as calculated with MIRDOSE3 [20].

The accumulated activity in the tumour was estimated from an ROI around the tumour in the last imaging study before surgery, using the partial background correction method as described previously [24]. This uptake was compared with the estimated activity as measured ex vivo. It was assumed that the amount of activity in the tumour was acquired instantaneously and remained constant. Because RIT will most likely be applied after debulking surgery $[12,13]$, it is important to estimate whether residual small tumour lesions can receive therapeutic doses. Therefore, for three patients, the calculated activity in large tumours, expressed as \% $\mathrm{ID} / \mathrm{g}$, following i.p. administration of ${ }^{131} \mathrm{I}-\mathrm{cMOv} 18-\mathrm{IgG}$, was assigned to tumours of $1 \mathrm{~g}$. For the 1-g tumours, the absorbed dose due to self-absorption of the non-penetrating $\beta$-radiation was calculated as the product of the residence time and the S-factor for a 1-g sphere (being 2.95E-02 mGy/MBq.s for ${ }^{131}$ I [25]), using the nodule module option of the MIRDOSE3 program [20].

The absorbed dose in 1-g tumours due to activity in the peritoneal cavity fluid was calculated as if the tumours were localised on the inner surface of the peritoneal cavity wall [12]. The peritoneal cavity wall was used as the surrogate for the small tumours for electron dose estimates due to activity in the peritoneal cavity fluid. The estimated dose in the tumours due to beta radiation from activity in the peritoneal cavity was calculated by multiplication of the dose rate factors for various distances from the peritoneal cavity into the cavity wall by the mean residence time of the activity in the peritoneal cavity fluid. A volume-distributed source in the peritoneal cavity was assumed, since prior to the i.p. administration of ${ }^{131} \mathrm{I}-\mathrm{cMoV} 18 \mathrm{IgG}$, a volume of approximately 1.51 of saline was infused into the peritoneal cavity [19].

\section{Results}

\section{Pharmacokinetics}

The concentration of radioactivity in the blood (\% ID/l) was not affected by the administered protein dose; therefore, the blood clearance data from all patients of each route of administration were pooled. The mean blood time-activity curves are shown in Fig. 1. For the i.p. route, the peak blood activity concentration was reached between 48 and $96 \mathrm{~h}$ p.i and averaged $10 \% \pm 2 \% \mathrm{ID} / \mathrm{l}$. Radioactivity in the blood was described by a bi-exponential curve with a mean half-life of $6.9 \pm 3.2 \mathrm{~h}$ p.i. for the accumulation phase and a mean half-life of $160 \pm 45 \mathrm{~h}$ for the elimination phase. For i.v. infusion, the blood data were described by a bi-exponential curve with a biological half-life for the elimination phase of $103 \pm 12 \mathrm{~h}$. The peak blood concentration, $23 \% \pm 6 \%$ ID/l, was reached at $3.0 \pm 0.4$ h p.i.

For both routes of administration the radioactivity appeared in the urine gradually. Maximum excretion was observed shortly after the maximum blood concentration had occurred. At $96 \mathrm{~h}$ after injection, the mean cumulative excretion of the radiolabel in the urine was $17 \% \pm 3 \%$ ID and $21 \% \pm 7 \%$ ID for i.p. and i.v. administration, respectively. For the i.v. route, the mean half-life for elimination of activity from the total body was $309 \mathrm{~h}$, based on the mean excretion of activity in the urine.

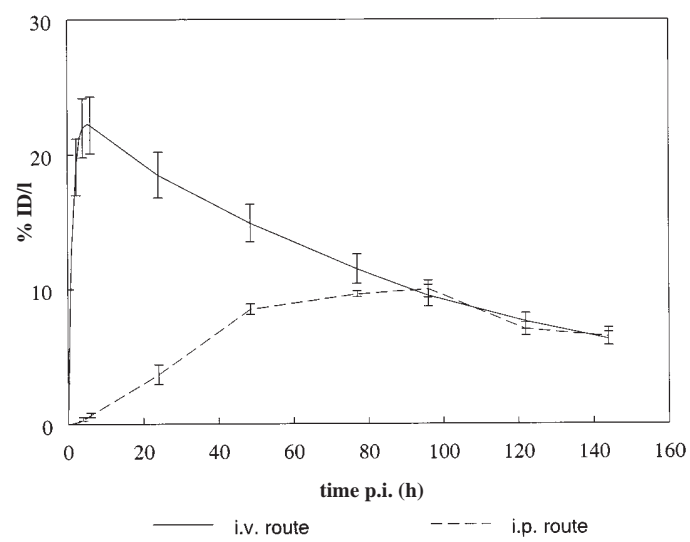

Fig. 1. Time-activity curves for the blood after i.p. $(n=8)$ and i.v. infusion $(n=4)$ of ${ }^{131} \mathrm{I}-\mathrm{cMOv} 18-\mathrm{IgG}$ in patients suspected of having ovarian cancer. Mean values \pm SEM (\% ID/l) 


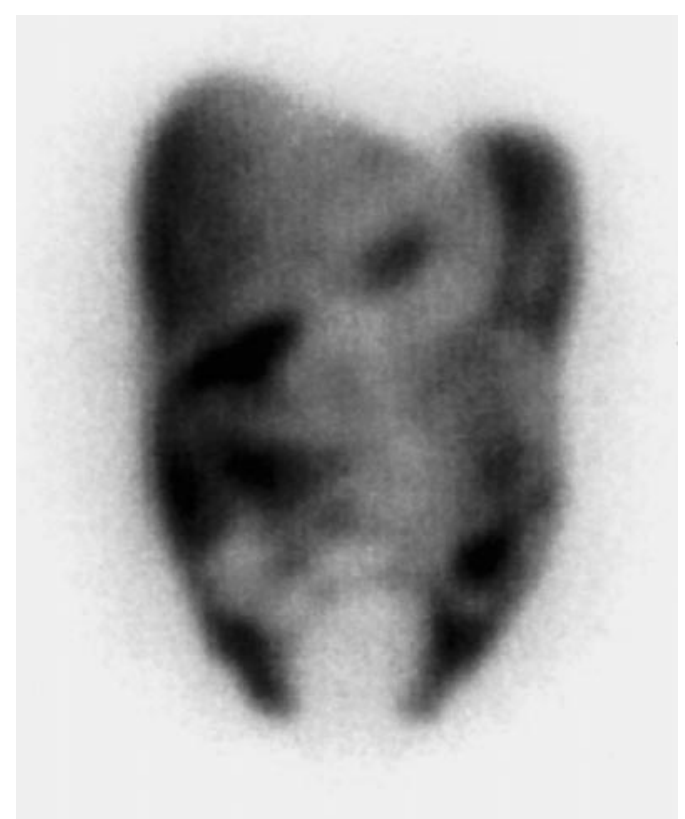

Fig. 2. Anterior planar image at $1 \mathrm{~h}$ p.i. showing the distribution of the radio-immunoconjugate through the peritoneal cavity

\section{Radioimmunoscintigraphy}

Eight patients were imaged after i.p. administration of ${ }^{131}$ I-cMOv18. Histological data of the tumours removed at surgery are summarized in Table 1 . Three patients had an epithelial ovarian cancer (nos. 2, 9 and 10), two patients were diagnosed as having a non-ovarian malignancy (nos. 3 and 5) and the remaining three patients had benign gynaecological tumours.

Immediately after intraperitoneal activity infusion, the estimated activity within the abdominal region was only $80 \%$ of the activity in the total body ROI. This is probably due to scattered radiation and penetration of the high-energy photons through the lead septa of the high-energy collimator. Therefore, the count rate in the abdomen ROI at the first image was set equal to $100 \%$ ID, while on subsequent images, the count rate within the abdomen ROI was divided by a factor of 0.8 in order to correct for scatter and collimator penetration.

In all patients, the radioimmunoconjugate diffused throughout the peritoneal cavity as observed on the 1-h p.i. images (Fig. 2). Up until 24 h p.i., the radioactivity was confined to the peritoneal cavity. At later time points the radioactivity appeared in the circulation. All ovarian carcinoma lesions that were found at surgery were visualised in the three patients having epithelial ovarian cancer. A typical example of such an image is shown in Fig. 3. None of the benign ovarian tumours $(n=3)$ showed elevated uptake. In addition, no elevated uptake was seen in the patient with an endometrium corpus carcinoma or the patient with a non-Hodgkin's lymphoma. After the radioimmunoconjugate had reached its maximum blood level, no retention of activity was seen in normal organs such as liver, kidneys or bone marrow.

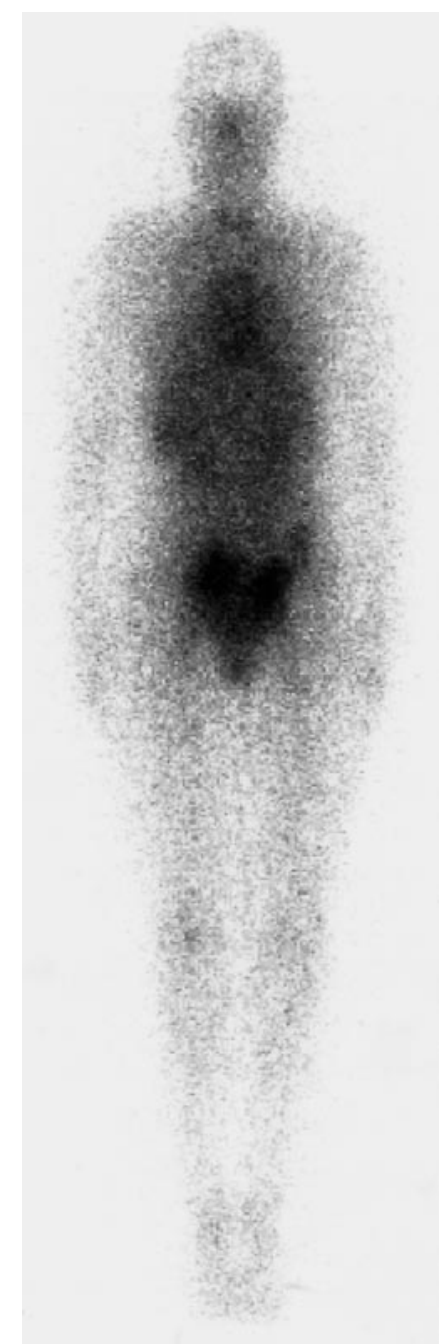

Fig. 3. Anterior planar image at 144 h p.i. of a patient with a serous adenocarcinoma of both ovaries showing elevated tumour uptake

\section{Tumour uptake}

After i.p. administration the uptake in the tumour deposits in the three patients having malignant ovarian cancer, as measured ex vivo, ranged from $3.4 \%$ to $12.3 \% \mathrm{ID} / \mathrm{kg}$, corresponding to a total uptake in the resected tumours of $3.3 \%, 2.8 \%$ and $1.8 \%$ ID. From gamma camera images the uptake in these tumours was estimated as $3.0 \%$, $3.1 \%$ and $2.6 \%$ ID. The uptake in benign tumours ranged from $0.5 \%$ to $1.8 \% \mathrm{ID} / \mathrm{kg}$. Uptake in non-ovarian malignancies varied from $0.1 \%$ to $2.1 \% \mathrm{ID} / \mathrm{kg}$. Mean uptake in muscle tissue was $1.4 \% \pm 0.5 \% \mathrm{ID} / \mathrm{kg}$. The tumour-to-muscle ratios ranged from 3 to 8 in patients with malignant ovarian tumours, whereas in the patients with benign tumours this ratio varied from 0.1 to 1.3 . In the patients with a non-ovarian malignancy the tumourto-muscle ratios ranged from 0.1 to 2.6 .

For the i.v. route of administration the uptake in malignant ovarian tumour deposits ranged from $3.6 \%$ to $5.4 \% \mathrm{ID} / \mathrm{kg}$. The tumour-to-non-tumour ratio ranged from 1.3 to 2.7 . 
Table 3. Retention in total body, abdomen and peritoneal cavity based on ROI measurements after i.p. administration

\begin{tabular}{lllll}
\hline \multirow{2}{*}{$\begin{array}{l}\text { Time p.i. } \\
\text { (h) }\end{array}$} & $\begin{array}{l}\text { No. of } \\
\text { patients }\end{array}$ & \multicolumn{2}{l}{ Retention } & \\
\cline { 3 - 5 } & & Total body & Abdomen & Peritoneal cavity \\
\hline 1 & 8 & 100 & $100 \pm 0$ & $99 \pm 2$ \\
24 & 7 & $94 \pm 4$ & $86 \pm 10$ & $80 \pm 13$ \\
48 & 6 & $91 \pm 6$ & $60 \pm 11$ & $50 \pm 13$ \\
72 & 5 & $84 \pm 4$ & $45 \pm 5$ & $35 \pm 3$ \\
120 & 7 & $71 \pm 10$ & $33 \pm 5$ & $24 \pm 6$ \\
144 & 6 & $63 \pm 7$ & $29 \pm 3$ & $20 \pm 4$ \\
\hline
\end{tabular}

a Expressed as percentage of the total body activity directly after i.p. injection (\% ID). Mean values \pm s.d.

\section{Organ doses}

The retention of activity in total body, the abdomen and the peritoneal cavity for the i.p. route of administration are summarized in Table 3 . Mean total body retention was $63 \% \pm 7 \%$ ID at $144 \mathrm{~h}$ p.i. The whole-body biological half-life ranged from 104 to $590 \mathrm{~h}$. The retention of activity in the peritoneal cavity was $20 \% \pm 4 \%$ ID after $144 \mathrm{~h}$ p.i. The residence times of the urinary bladder and the "rest of the body" were $0.44 \pm 0.16$ and $80 \pm 22 \mathrm{~h}$, respectively. The absorbed doses for the target organs ranged from $0.35 \mathrm{mSv} / \mathrm{MBq}$ for the lungs to $1.59 \mathrm{mGy} / \mathrm{MBq}$ for the pancreas (Table 4). The contribution of the activity in the peritoneal cavity to the total absorbed doses in the abdominal organs ranged from
$39 \%-82 \%$ (Table 4 ). The absorbed dose to the target organs after i.v. administration ranged from $0.40 \mathrm{mSv} /$ $\mathrm{MBq}$ for the skin to $0.57 \mathrm{mSv} / \mathrm{MBq}$ for the red marrow. The absorbed dose to the lungs was $0.49 \mathrm{mSv} / \mathrm{MBq}$.

\section{Red marrow dose}

The mean residence time for the red marrow based on the pooled blood time-activity data was $3.05 \mathrm{~h}$ after i.p. administration of ${ }^{131} \mathrm{I}-\mathrm{cMOv} 18 \mathrm{IgG}$. The mean absorbed dose in the red marrow was $0.49 \pm 0.04 \mathrm{mGy} / \mathrm{MBq}$. The contribution from the activity in the peritoneal cavity to the total red marrow dose was 32\% (Table 4). Assuming that an absorbed dose of $2 \mathrm{~Gy}$ in the red marrow is the maximum dose that will not induce grade 4 toxicity (MTD), $4.1 \mathrm{GBq}$ of ${ }^{131} \mathrm{I}$-cMOv18 IgG could be administered safely.

For i.v. administration, the absorbed dose in the red marrow based on the pooled blood time-activity data was $0.57 \mathrm{mGy} / \mathrm{MBq}$, and thus for this route of administration a maximal tolerable dose of $3.5 \mathrm{GBq}^{131} \mathrm{I}-$ cMOv18 IgG was estimated.

\section{Effective dose}

Following i.p. administration, the effective dose, based on the mean organ doses, was $0.55 \mathrm{mSv} / \mathrm{MBq}$, resulting in an effective dose of $82 \mathrm{mSv}$ for the $150 \mathrm{MBq}{ }^{131} \mathrm{I}-$ cMOv18 $\operatorname{IgG}$ administered in this study. For the i.v. route of administration the effective dose was
Table 4. Absorbed dose in target organs from activity in the peritoneal cavity and in the "total body minus peritoneal cavity" after i.p. administration

\begin{tabular}{lllll}
\hline Organ & $\begin{array}{l}\text { Dose due to } \\
\text { activity in the } \\
\text { peritoneal cavity } \\
(\mathrm{mGy} / \mathrm{MBq})\end{array}$ & $\begin{array}{l}\text { Dose due to } \\
\text { activity in the } \\
\text { "total body } \\
\text { minus peritoneal } \\
\text { cavity" } \\
\text { (mGy/MBq) }\end{array}$ & $\begin{array}{l}\text { Total absorbed } \\
\text { dose } \\
(\mathrm{mGy} / \mathrm{MBq})\end{array}$ & $\begin{array}{l}\text { Peritoneal } \\
\text { contribution } \\
(\%)\end{array}$ \\
& & & \\
& & $0.28 \pm 0.07$ & $0.73 \pm 0.08$ & $62 \pm 7$ \\
Adrenals & $0.45 \pm 0.06$ & $0.32 \pm 0.11$ & $0.85 \pm 0.1$ & $64 \pm 9$ \\
Small intestine & $0.54 \pm 0.07$ & $0.27 \pm 0.07$ & $0.61 \pm 0.07$ & $55 \pm 7$ \\
Stomach & $0.33 \pm 0.05$ & $0.33 \pm 0.12$ & $0.63 \pm 0.1$ & $50 \pm 9$ \\
Colon & $0.31 \pm 0.04$ & $0.27 \pm 0.06$ & $0.63 \pm 0.07$ & $58 \pm 7$ \\
Kidneys & $0.36 \pm 0.05$ & $0.27 \pm 0.06$ & $0.57 \pm 0.07$ & $53 \pm 7$ \\
Liver & $0.30 \pm 0.04$ & $0.26 \pm 0.05$ & $0.35 \pm 0.05$ & $26 \pm 5$ \\
Lungs & $0.09 \pm 0.01$ & $0.29 \pm 0.06$ & $0.65 \pm 0.07$ & $55 \pm 6$ \\
Ovaries & $0.36 \pm 0.05$ & $0.28 \pm 0.06$ & $1.59 \pm 0.17$ & $82 \pm 4$ \\
Pancreas & $1.31 \pm 0.16$ & $0.33 \pm 0.07$ & $0.49 \pm 0.04$ & $32 \pm 4$ \\
Red marrow & $0.16 \pm 0.02$ & $0.28 \pm 0.07$ & $0.37 \pm 0.07$ & $25 \pm 5$ \\
Bone surfaces & $0.09 \pm 0.01$ & $0.27 \pm 0.06$ & $0.46 \pm 0.06$ & $43 \pm 7$ \\
Spleen & $0.20 \pm 0.03$ & $0.38 \pm 0.11$ & $0.61 \pm 0.10$ & $39 \pm 9$ \\
Urinary bladder & $0.23 \pm 0.03$ & & & \\
& & & & \\
\end{tabular}

a With respect to dosimetry, ovaries were used as the surrogate for tumours. Only absorbed dose to the ovaries due to penetrating radiation is presented. The mean absorbed dose to the ovaries is derived from the five patients having no malignant tumour. For all other organs the contribution of activity in the tumour to the absorbed dose is included. The absorbed dose to these organs is averaged over eight patients 
Table 5. Electron doses in the tumour wall from volume distributed sources of ${ }^{131} \mathrm{I}$ after i.p. administration

\begin{tabular}{llll}
\hline $\begin{array}{l}\text { Distance from } \\
\text { peritoneal cavity } \\
\text { into peritonial } \\
\text { cavity wall } \\
(\mathrm{cm})\end{array}$ & $\begin{array}{l}\text { Volume source } \\
\text { electron dose } \\
(\mathrm{mGy}-\mathrm{g} / \mathrm{MBq}-\mathrm{sec})\end{array}$ & $\begin{array}{l}\text { Dose rate for } \\
\text { volume 1500 } \mathrm{gb} \\
(\mathrm{mGy} / \mathrm{MBq})\end{array}$ & $\begin{array}{l}\text { Absorbed dose } \\
\text { for 4.1 GBq } \\
(\mathrm{Gy})\end{array}$ \\
\hline 0.000 & & & \\
0.001 & 0.015 & 3.00 & 12.3 \\
0.003 & 0.014 & 2.80 & 11.4 \\
0.006 & 0.011 & 2.20 & 9.0 \\
0.018 & 0.009 & 1.80 & 7.4 \\
0.030 & 0.005 & 1.00 & 4.1 \\
0.050 & 0.0028 & 0.56 & 2.3 \\
0.080 & 0.00105 & 0.21 & 0.86 \\
\hline
\end{tabular}

a Data in columns 1 and 2 were derived from Watson et al. [19]

${ }^{b}$ For each distance, data in column 3 were calculated using the formula: (data column 2$) \times$ (mean residence time for peritoneal cavity: $83.3 \mathrm{~h}) \times(3600[\mathrm{~s} / \mathrm{h}]) /(1500[\mathrm{~g}])$
$0.52 \mathrm{mSv} / \mathrm{MBq}$, resulting in an effective dose of $3.9 \mathrm{mSv}$ after administration of $7.5 \mathrm{MBq}{ }^{131} \mathrm{I}-\mathrm{cMOv} 18 \mathrm{IgG}$.

\section{Tumour dose}

For the i.p. route of administration the tumour absorbed dose due to penetrating radiation was $0.65 \pm$ $0.07 \mathrm{mGy} / \mathrm{MBq}$ (Table 4). For i.v. administration the tumour absorbed dose due to activity in the whole body was $0.57 \mathrm{mSv} / \mathrm{MBq}$. Thus, the additional dose to the tumour due to penetrating radiation after i.p. administration of $4.1 \mathrm{GBq}$ of ${ }^{131} \mathrm{I}-\mathrm{cMOv} 18$ will be $2.7 \mathrm{~Gy}$, while the additional dose to the tumour following i.v. administration of $3.5 \mathrm{GBq}$ of ${ }^{131} \mathrm{I}-\mathrm{cMOv} 18$ will be $1.9 \mathrm{~Gy}$.

For i.p. administration, the residence time of the large tumours, as measured ex vivo, ranged from 9.4 to $34.0 \mathrm{~h} / \mathrm{kg}$, and thus from 0.0094 to $0.034 \mathrm{~h}$ for $1-\mathrm{g}$ tumours. The absorbed doses to 1 -g lesions due to nonpenetrating radiation ranged from 1.0 to $3.6 \mathrm{mGy} / \mathrm{MBq}$. For an administered activity of $4.1 \mathrm{GBq}$ a maximum of 15 Gy could be delivered to these tumour lesions due to self-absorption of the beta-radiation. For the i.v. route, the residence time for large tumours ranged from 10 to $15 \mathrm{~h} / \mathrm{kg}$, based on an initial uptake varying from $3.6 \%$ to $5.4 \% \mathrm{ID} / \mathrm{kg}$. The absorbed dose to the $1-\mathrm{g}$ tumours ranged from 1.1 to $1.6 \mathrm{mGy} / \mathrm{MBq}$, due to self-absorption. Therefore, $3.5 \mathrm{GBq}^{131} \mathrm{I}-\mathrm{cMOv} 18 \mathrm{IgG}$ administered intravenously would result in a maximum absorbed dose of 5.6 Gy to these tumours for self-absorption only.

The dose rate from electrons emitted by the activity present in the peritoneal cavity surrounding the tumour ranged from $3.0 \pm 0.4 \mathrm{mGy} / \mathrm{MBq}$ at the tumour surface to $1.0 \pm 0.1 \mathrm{mGy} / \mathrm{MBq}$ at a distance of $0.2 \mathrm{~mm}$ from peritoneal cavity into the tumour. At a distance of $1 \mathrm{~mm}$ from the peritoneal cavity into the tumour the dose rate was less than $0.03 \mathrm{mGy} / \mathrm{MBq}$ (Table 5). For an administered activity of $4.1 \mathrm{GBq}^{131} \mathrm{I}-\mathrm{cMOv} 18 \mathrm{IgG}$ via the i.p. route, the absorbed electron dose ranged from $12.3 \mathrm{~Gy}$ at the tumour surface to $4.1 \mathrm{~Gy}$ at a distance of $0.2 \mathrm{~mm}$ from the intraperitoneal cavity into the tumour.

The total dose to the tumour was calculated as the sum of the dose from penetrating radiation and nonpenetrating radiation in the tumour due to self-absorption of the activity in the tumour itself. For the i.p. route of administration the total dose ranged from 1.7 to $4.3 \mathrm{mGy} / \mathrm{MBq}$. For the i.v. route of administration this range was 1.7-2.2 $\mathrm{mGy} / \mathrm{MBq}$. At MTD (4.1 GBq i.p.) a maximum dose of 18 Gy could be delivered to the tumour. If the electron dose to the tumour from peritoneal activity is also taken into account, a total absorbed dose of 30 Gy can be reached at the tumour surface and a dose of 22 Gy at $0.2 \mathrm{~mm}$ depth.

For the i.v. route of administration a maximum absorbed dose of $8 \mathrm{~Gy}$ could be delivered to the tumour after injection of $3.5 \mathrm{GBq}^{131} \mathrm{I}-\mathrm{cMOv} 18 \mathrm{IgG}$.

\section{Discussion}

The aim of the present study was to investigate the dosimetry associated with the i.p. and i.v. administration of radioiodinated cMOv18 $\mathrm{IgG}$ in ovarian cancer patients.

\section{Pharmacokinetics and biodistribution}

Planar images showed good distribution throughout the peritoneal cavity in all patients following i.p. administration of ${ }^{131} \mathrm{I}-\mathrm{cMOv} 18 \mathrm{IgG}$.

The mean whole-body retention measured $84 \%$ and $80 \%$ ID at 96 h p.i. after i.p. and i.v. injection, respectively. Crippa et al. reported a much faster whole-body excretion of the murine MOv18 MAb after i.p. administration: $20 \%$ ID was present in the total body at $96 \mathrm{~h}$ p.i. [1]. Crippa et al. used a 1-mg protein dose, while in the present study 15-80 mg was administered. This suggests that at very low protein doses the whole-body clearance 
may be enhanced. We have observed this same phenomenon with the cG250 antibody. This antibody also cleared faster when $2 \mathrm{mg}$ was administered as a protein dose as compared to doses $\geq 5 \mathrm{mg}$ [26]. Immunohistological studies in experimental tumour models have shown that higher protein doses of antibody may enhance the tumour penetration. Therefore, unless antigen saturation occurs, high protein doses may be more optimal for RIT [12].

Tumour uptake. Comparison of tumour uptake derived from gamma camera images and uptake determined ex vivo after i.p. administration showed an excellent correlation: in three patients an uptake of $3.0 \%, 3.1 \%$ and $2.6 \%$ ID was derived from gamma camera ROIs, while the ex-vivo measurements of these tumours indicated an uptake of $3.3 \%, 2.8 \%$ and $1.8 \%$ ID, respectively.

Tumour dosimetry. After completing the course of chemotherapy, ovarian cancer patients may undergo secondlook laparotomy (SLL) to assess their disease status. Persistent disease diagnosed by SLL has been observed in $45 \%-80 \%$ of patients with advanced disease [27]. However, negative findings at SLL are not a definitive sign of tumour eradication. Within 5 years, $24 \%$ of the patients with a negative SLL presented recurrent disease [28]. In these situations small tumours or metastases may be present in the peritoneal cavity, on the peritoneal cavity wall or in the small intestine. Therefore, for the i.p. route of administration, special attention was given to estimate the absorbed dose to small tumours $[12,13]$.

The absorbed dose estimations were based on the assumptions that the tumour uptake level and the tumour residence time per gram tissue in small tumour deposits will be the same as in large tumours. This is a conservative approximation: several studies have shown that antibody uptake is higher in small tumours [12, 13, 29]. Comparing tumours of different sizes (e.g. 1-1000 g), but with equal uptake of activity $\left.{ }^{131} \mathrm{I}\right)$ per gram, the dose to small tumours will be $25 \%$ lower than that to large tumours, due to a higher self-absorption of photon energy in the large tumours [25]. Moreover, in micrometastases with clusters of tumour cells $(10 \mu \mathrm{m}$ radius spheres) part of the beta-energy from activity in the tumour will not be absorbed in the small spheres, resulting in lower doses, depending on the radionuclide used [12, 25]. However, cross-radiation from the beta-radiation emitted by the activity in the peritoneal cavity after i.p. administration of ${ }^{131} \mathrm{I}-\mathrm{cMOv} 18 \mathrm{IgG}$ may increase the absorbed dose in these small tumours.

In the present study, the absorbed dose in the tumours varied from 1.7 to 4.3 and 1.7 to $2.2 \mathrm{mGy} / \mathrm{MBq}$ after i.p. and i.v. administration, respectively. This is in the same range as was reported by Behr et al (2-4 mGy/MBq) after i.v. administration of ${ }^{131} \mathrm{I}$-labelled IgG anti-CEA antibodies in CEA-expressing cancers [10]. For the i.p. route of administration the tumour dose may be enhanced with $3 \mathrm{mGy} / \mathrm{MBq}$ at the tumour surface and $1 \mathrm{mGy} / \mathrm{MBq}$ at
$0.2 \mathrm{~mm}$ depth in the tumours, due to the electron dose from activity in the peritoneal cavity [19]. Thus, including the electron dose due to activity in the peritoneal cavity in the dose estimates, absorbed doses of 30 and 22 Gy can be reached at the tumour surface and at $0.2 \mathrm{~mm}$ depth in the tumour, respectively.

\section{Intraperitoneal versus intravenous administration}

The area under the blood time-activity curve from time of administration to time of surgery (AUC, biological) was estimated as 10 and $21 \mathrm{~h} / \mathrm{l}$ for the i.p. route and the i.v. route, respectively. If MAb blood level were the driving force for antibody accumulation in tumours, the tumour uptake would be expected to be at least as high or even a factor of 2 higher after i.v. administration than after i.p. administration. However, such a relation was not found in our study: the uptake in ovarian carcinoma tumours, measured ex vivo, ranged from $3.4 \%$ to $12.3 \%$ ID $/ \mathrm{kg}$ and from $3.6 \%$ to $5.4 \%$ ID $/ \mathrm{kg}$ for the i.p. and i.v. routes of administration, respectively. The tumour uptake data in the current study are in accordance with findings of previous clinical studies reporting higher tumour uptake after i.p. administration as compared to i.v. injection [1, 9]. Crippa et al. [1] also found a more favourable biodistribution after i.p. administration of murine ${ }^{131} \mathrm{I}$ MOv18 than after i.v. administration. These data suggest that possibly direct tumour uptake after i.p. administration (non-systemic supply) causes the major part of the uptake of the antibody in the tumour. Another main advantage of locoregional administration is the reduced uptake in normal tissues, e.g. lungs and red marrow. In this study, the mean estimated radiation doses to the lungs were 0.35 and $0.49 \mathrm{mGy} / \mathrm{MBq}$ after i.p. administration and i.v. administration, respectively. For the red marrow the absorbed doses were 0.49 and $0.57 \mathrm{mGy} / \mathrm{MBq}$, respectively. In addition, in the case of RIT the relatively long retention in the peritoneal cavity may result in an increased absorbed dose to small tumour nodules on the peritoneal wall and on the intestine due to the prolonged bathing in a radiolabelled MAb fluid.

In general, the accuracy of tumour dose calculations is limited due to factors such as assumption of uniform distribution of activity throughout a tumour and the inaccurate assumption of initial uptake [30]. In the current study it was assumed that the activity in the tumour, found at surgery, was instantaneously present at the time of administration [31]. Only physical decay was considered. For the i.p. route of administration the count rate in the tumour ROI on the gamma camera images increased during the first $24-48 \mathrm{~h}$ after injection and was stable on later images. Thus, the assumption of initial uptake in the tumour may have led to a minor overestimation of the absorbed dose. Such an overestimation may be counteracted by a likely increase of activity in the period after 7 days p.i. if no surgery would be performed. 
In summary, the data from this study suggest that the i.p. route of administration is preferable to the i.v. route.

\section{Use of tracer dose images to predict therapy doses}

Tumour uptake and, consequently, the radiation dose to the tumour seem to vary considerably between patients $[10,11,31]$. Based on the dosimetric analysis of the data obtained after i.p. injection of ${ }^{131} \mathrm{I}$-labelled B72.3 $\mathrm{IgG}$ in ten patients with adenocarcinoma, Larson et al. recommended that the radiation dose should be estimated on an individual basis using a diagnostic dose in order to determine the efficacy of a therapeutic dose [31]. Other authors have confirmed the necessity of this approach [32-35]. Haematopoietic toxicity is usually the doselimiting factor in RIT [21, 31, 35, 36]. For bone marrow, $2 \mathrm{~Gy}$ is considered to be the maximum tolerated dose [31]. Our calculations indicate that the radiation dose to the marrow will amount to an MTD of $2 \mathrm{~Gy}$, after administration of 4.1 or $3.5 \mathrm{GBq}$ for i.p. and i.v. administration, respectively. Extrapolating the dosimetric data of the tumours measured ex vivo in the current study, the maximum radiation dose to 1 -g tumour deposits was estimated to be $18 \mathrm{~Gy}$ at a $4.1 \mathrm{GBq}$ dose for the i.p. route and $8 \mathrm{~Gy}$ at a $3.5 \mathrm{GBq}$ dose for the i.v. route of administration. After i.p. administration of $4.1 \mathrm{GBq}$, an additional dose of 12 and 4 Gy can be absorbed at the tumour surface and at a depth of $0.2 \mathrm{~mm}$, respectively.

An absorbed dose of $20 \mathrm{~Gy}$ is considered a tumoursterilising level for tumours with a diameter of $0.3 \mathrm{~mm}$ [12], and thus ${ }^{131} \mathrm{I}$-cMov18-IgG could potentially induce therapeutic response, especially upon i.p. administration.

In clinical patient management it is usually impractical to collect data for blood, urine and tissue uptake for more than a few days. The calculation of the residence times in the organs or tumours was therefore based on the limited data for uptake of activity in the organs during the sampling period, which will result in inaccurate estimates of the absorbed dose. If the sampling period is less than or equal to the effective half-time of the radiopharmaceutical, the error in the estimated dose may exceed $100 \%$. To reduce these errors, application of physical, biological or mathematical models for the timeactivity curves [37, 38] and use of special computer programs [39] may be helpful, permitting more accurate determination of the residence times and absorbed doses.

In conclusion, the concept of targeting radiolabelled antibodies towards tumour cells remains an attractive therapy concept for ovarian cancer patients. The i.p. route of administration seems to be preferable to i.v. administration: tumour uptake is at least as high after i.p. administration while haematopoietic toxicity is reduced. Chimeric MOv18 IgG seems to offer a therapeutic advantage particularly in patients with small tumour deposits.
Acknowledgements. We are grateful to Dr. K.G.G. Keijser, gynaecologist, and the nursery staff of the Gynaecology ward for their excellent care of the participating patients. We would like to thank A. Meeuwis, D.J. Immerzeel and P. Kok for imaging.

\section{References}

1. Crippa F, Buraggi GL, Di Re E, et al. Radioimmunoscintigraphy of ovarian cancer with the MOv18 monoclonal antibody. Eur J Cancer 1991; 27: 724-729

2. Molthoff CF, Buist MR, Kenemans P, Pinedo HM, Boven E. Experimental and clinical analysis of the characteristics of a chimeric monoclonal antibody, MOv18, reactive with an ovarian cancer-associated antigen. J Nucl Med 1992; 33: 2000-2005.

3. Buist MR, Kenemans P, den Hollander W, Vermorken JB, et al. Kinetics and tissue distribution of the radiolabeled chimeric monoclonal antibody MOv18 $\operatorname{IgG}$ and $\mathrm{F}(\mathrm{ab})_{2}$ fragments in ovarian carcinoma patients. Cancer Res 1993; 53: 5413-5418.

4. Boerman OC, van Niekerk CC, Makkink K, Hanselaar AGJM, Kenemans P, Poels LG. A comparative immunohistochemical study of four monoclonal antibodies directed against ovarian carcinoma-associated antigens. Int J Gynaecol Pathol 1991; 10: $15-25$.

5. Epenetos AA, Munro AJ, Stewart S, et al. Antibody-guided irradiation of advanced ovarian cancer with intraperitoneally administered radiolabeled monoclonal antibodies. J Clin Oncol 1987; 5: 1890-1899.

6. Stewart JSW, Hird V, Snook D, et al. Intraperitoneal yttrium90-labeled monoclonal antibody in ovarian cancer. J Clin Oncol 1990; 8: 1941-1950.

7. DeNardo DA, DeNardo GL, O'Donell RT, et al. Imaging for improved prediction of myelotoxicity after radioimmunotherapy. Cancer 1997; 80: 2558-2566.

8. Eary JF. Fundamentals of radioimmunotherapy. Nucl Med Biol 1991; 18: 105-108.

9. Tibben JG, Massuger LFAG, Boerman OC, Borm GF, Claessens RAMJ, Corstens FHM. Effect of the route of administration on the biodistribution of radioiodinated OV-TL $3 \mathrm{~F}\left(\mathrm{ab}^{\prime}\right)_{2}$ in experimental ovarian cancer. Eur J Nucl Med 1994; 21: 1183-1190.

10. Behr TM, Sharkey RM, Juweid ME, et al. Variables influencing tumor dosimetry in radioimmotherapy of CEA-expressing cancers with anti-CEA and antimucin monoclonal antibdies. $J$ Nucl Med 1997; 38: 409-418.

11. Siegel JA, Pawlyk DA, Lee RE, et al. Tumour, red marrow, and organ dosimetry for ${ }^{131} \mathrm{I}$-labeled anti-carcinoembryonic antigen monoclonal antibody. Cancer Res 1990; 50: 1039s1042s.

12. Britton KE, Mather SJ, Granowska M. Radiolabelled monoclonal antibodies in oncology. III. Radioimmunotherapy. Nucl Med Commun 1991; 12: 333-347.

13. Behr TM, Sharkey RM, Juweid ME, et al. Phase I/II clinical radioimmunotherapy with an iodine-131-labeled anti-carcinoembryonic antigen murine monoclonal antibody IgG. $\mathrm{J} \mathrm{Nucl}$ Med 1997; 38: 858-870.

14. Molthoff CFM, Prinssen HM, Kenemans P, van Hof AC, den Hollander W, Verheijen RHM. Escalating protein doses of chimeric monoclonal antibody MOv18 immunoglobulin G in ovarian carcinoma patients: a phase I study. Cancer 1997; 80: 2712-2720.

15. MIRD Primer For Absorbed Dose Calculations. Prepared by Robert Loevinger, Thomas F. Budinger and Evelyn E.Watson. The Society of Nuclear Medicine, 1988. 
16. Buijs WCAM, Massuger LFAG, Claessens RAMJ, Kenemans P, Corstens FHM. Dosimetric evaluation of immunoscintigraphy using indium-111-labeled monoclonal antibody fragments in patients with ovarian cancer. J Nucl Med 1992; 33: $1113-1120$.

17. ICRP Publication 23. Report of the task group on reference man. Oxford: Pergamon Press, 1975.

18. ICRP Publication 53. Radiation dose to patients from radiopharmaceuticals. Oxford: Pergamon Press, 1988.

19. Watson EE, Stabin MG, Davis JL, Eckerman KF. A model of the peritoneal cavity for use in internal dosimetry. J Nucl Med 1989; 30: 2002-2011.

20. Stabin MG. MIRDOSE: personal computer software for internal dose assessment in nuclear medicine. J Nucl Med 1996; 37: 538-546.

21. Siegel JA, Wessels BW, Watson EE, et al. Bone marrow dosimetry and toxicity for radioimmunotherapy. Antibody Immunoconj Radiopharm 1990; 3: 213-233.

22. Buijs WCAM, Steffens MG, Boerman OC, Oosterwijk E, Siegel JA, Corstens FHM. Estimation of absorbed red marrow dose after administration of 131-I-cG250. Eur J Nucl Med 1997; 24: 868s.

23. ICRP Publication 60. 1990 Recommendations of the International Commission on Radiological Protection. Oxford: Pergamon Press; 1991.

24. Buijs WCAM, Siegel JA, Boerman OC, Corstens FHM. Estimation of absolute organ activity using five different methods of background correction. J Nucl Med 1998; in press.

25. Siegel JA, Stabin MG. Absorbed fractions for electrons and beta particles in spheres of various sizes. J Nucl Med 1994; 35: $152-156$.

26. Steffens MG, Boerman OC, Oosterwijk-Wakka JC, et al. Targeting of renal cell carcinoma with iodine-131-labeled chimeric monoclonal antibody G250. J Clin Oncol 1997; 15: $1529-1537$.

27. Copeland LJ, Gershenson DM, Wharton JT, et al. Microscopic disease at second-look laparotomy in advanced ovarian cancer. Cancer 1985; 55: 472-478.

28. Gershenson DM, Copeland LJ, Wharton JT, et al. Prognosis of surgically determined complete responders in advanced ovarian cancer. Cancer 1985; 55: 1129-1135.
29. Van Hof AC, Molthoff CFM, Davies Q, et al. Biodistribution of ${ }^{111}$ In-labeled engineered human antibody CTMO1 in ovarian cancer patients: influence of protein dose. Cancer Res. 1996; 56: 5179-5185.

30. Flower MA, McCready VR. Radionuclide therapy dose calculations: what accuracy can be achieved? Eur J Nucl Med 1997; 24: 1462-1464.

31. Larson SM, Carrasquillo JA, Colcher DC, et al. Estimates of radiation absorbed dose for intraperitoneally administered iodine-131 radiolabeled B72.3 monoclonal antibody in patients with peritoneal carcinomatoses. J Nucl Med 1991; 32: 1661-1667.

32. Juweid M, Sharkey RM, Goldenberg DM. Patient specific (PS) estimates of red marrow dose result in improved correlation with myelotoxicity. J Nucl Med 1998; 39: 112P.

33. Erdi AK, Erdi YE, Yorke ED, Wessels BW. Treatment planning for radio-immunotherapy. Phys Med Biol 1996; 41: 2009-2026.

34. Kaminski MS, Fig LM, Zasadny KR, et al. Imaging, dosimetry and radioimmunotherapy with iodine 131-labeled antiCD37 antibody in B-cell Lymphoma. J Clin Oncol 1992; 10: 1696-1711.

35. Eary JF, Krohn KA, Press OW, Durack L, Bernstein ID. Importance of pre-treatment radiation absorbed dose estimation for radioimmunotherapy of non-Hodgkin's lymphoma. Nucl Med Biol 1997; 24: 635-638.

36. Fisher DR. Radiation dosimetry for radioimmunotherapy. Cancer 1994; 73: 905-911.

37. Selikson MH, Jaggi J, Mozley PD, et al. A proposal for minimum detectable compartment in MIRD dosimetry modelling. Phys Med Biol 1997; 42: 1605-1617.

38. Sgouros G, Graham MC, Divgi CR, Larson SM, Scheinberg DA. Modeling and dosimetry of monoclonal antibody M195 (anti-CD33) in acute myelogenous leukemia. J Nucl Med 1993; 34: 422-430.

39. Herzog H, Zilken H, Niederbremer A, Friedrich W, MullerGartner HW. Calculation of residence times and radiation doses using standard PC software Excel. Eur J Nucl Med 1997; 24: $1514-1521$. 